\title{
PAS BESOIN DE GRIL O ESTATUTO JURÍDICO DA MULTIPROPRIEDADE IMOBILIÁRIA SEGUNDO O JULGAMENTO DO RESP 1.546.165/SP
}

André Luiz Arnt Ramos* Eroulths Cortiano Junior**

Sumário: Introdução - 1. Direito real e segurança jurídica para além do numerus clausus (?) - Conclusão - Referências.

\section{INTRODUÇÃO}

A Terceira Turma do Superior Tribunal de Justiça, ao apreciar o Recurso Especial n. 1.546.165/SP, sob relatoria originária do Min. Ricardo Villas Bôas Cueva, foi instada a se pronunciar a respeito de duas questôes: (i) A multipropriedade credencia qualquer dos titulares à oposição de embargos de terceiro em face de constrição judicial do bem ou de fração sua?; e (ii) A multipropriedade imobiliária configura direito real ou plexo de direitos pessoais de conteúdo patrimonial? Em votação dividida, respondeu afirmativamente à primeira e, quanto à segunda, registrou que vislumbra caráter real na multipropriedade imobiliária.

O resultado deste julgamento tem impacto decisivo e imediato sobre o governo jurídico das titularidades, na precisa medida em que abala uma de suas vetustas

\footnotetext{
* Doutorando e Mestre em Direito das Relaçōes Sociais e Bacharel em Direito pela UFPR. Visting researcher junto ao Instituto Max Planck para Direito Comparado e Internacional privado. Membro do Grupo de Pesquisa Virada de Copérnico - Eixo de Titularidades. Associado ao Instituto dos Advogados do Paraná. Professor da Universidade Positivo. Advogado em Curitiba.

** Doutor em Direito pela UFPR. Pós-doutor pela Università degli Studi di Torino. Professor da Faculdade de Direito da UFPR. Líder do Grupo de Pesquisa Virada de Copérnico.
} 
pedras de toque: a clausura real. Projeta efeitos, ademais, para o trânsito jurídico e para o projeto parental, de modo que alcança, em diferentes níveis de intensidade, aspectos de todos os tripés fundantes do Direito Civil.

Mas a disciplina jurídica das relações interprivadas que recebe este julgamento e passa a ser por ele integrado ${ }^{1}$ é bem diversa daquela cara ao contexto em que vicejavam as dicotomias estruturais e estruturantes entre Direito Público e Direito Privado $^{2}$, Constituição e Código Civil ${ }^{3}$, Direito e fato ${ }^{4}$, e direitos reais e direitos pessoais. O Direito Civil de hoje, forjado pelas viragens que marcam a travessia entre os modelos ${ }^{5}$ de Estado de Direito e Estado Constitucional, imbrica-se em

1 "Sendo parte integrante do ordenamento jurídico, o precedente deve ser levado em consideração como parâmetro necessário para aferição da igualdade de todos perante a ordem jurídica e para promoção de segurança jurídica. Isso implica, a uma, que todos os casos iguais sejam tratados de forma igual pela Corte Suprema e por todos os órgãos jurisdicionais a ela ligados a partir do conteúdo do precedente, e, a duas, que a exigência de cognoscibilidade inerente à segurança jurídica leve em consideração o processo de interpretação judicial do Direito e o seu resultado" (MITIDIERO, 2013, p. 76).

2 "Público e estatal não mais se identificam por inteiro; privatismo e individualismo, a seu turno, cedem espaço para os interesses sociais e para a 'coexistencialidade'. A superação da divisão em pauta não fere, necessariamente, a unidade sistemática do direito, inclusive porque ultrapassada também se encontra a fixação rígida de espaços normativos. (...) Constata-se, pois, uma mudança de paradigmas" (FACHIN, 2012, p. 242).

3 A ruína do valor performático do Código Civil consagra a Constituição como a sede dos ângulos e parâmetros do ordenamento, como "verdadeira parte geral do ordenamento jurídico, deixando de ser o estatuto do poder público para se converter na ordem jurídica fundamental da comunidade (...). Este contexto configura uma crise sem precedentes dos modelos teóricos comumente utilizados para compreensão da ciência jurídica, baseada tradicionalmente nas verdades universais de inspiração iluminista. (...). [Como consequência,] o Direito Civil deixa de ser o centro de regulação da ordem privada e o intérprete passa a se valer dos princípios constitucionais para a reunificação do sistema, especialmente a dignidade humana e a solidariedade, evitando antinomias provocadas por núcleos normativos díspares, correspondentes a lógicas setoriais nem sempre coerentes" (EHRHARDT JUNIOR, 2012, p. 150 e 152).

4 Duas citações, neste quesito, vêm a calhar: "A abertura da Teoria do Direito Civil impõe a intersecção com outros ramos do Direito e a porosidade aos fenômenos concretos objetos de normatização; a abertura do sistema jurídico, a seu turno, impõe a abertura do Direito à força normativa que emerge dos fatos, como resultado das demandas sociais" (PIANOVSKI RUZYK, 2013, p. 152-153). "Reclama-se (...) a compreensão do Direito como um sistema aberto, próximo à vida. Não se o pode conceber como um sistema fechado, autorreceptor de suas normas, independentemente de todo um meio ambiente que o cerca. A pretensão de autonomia da ciência jurídica - em relação aos valores morais, à economia, à política - fracassou, porque os fatos acabam por impor-se perante o Direito" (MATOS, 2012, p. 147).

5 “'Modelo constitucional", conquanto não corresponda, exatamente, a uma expressão valorativa, comporta pontual esclarecimento: "Por 'modelo constitucional', queremos dizer o conjunto de crenças médias, dos intérpretes, da classe política e dos cidadãos, a determinar a vida 
uma ordem normativa unitária e submetida a um bloco constitucional imantado por rica axiologia. Mais que isso: guarda estreita relação com a realidade fática, de modo que a condiciona, mas também é por ela condicionado ${ }^{6}$.

Nesta ordem de ideias, um novo modelo de Código, prenhe de inputs e outputs com o mundo que o circunda, substitui as pretensões normativas totalizantes de outrora ${ }^{7}$. Todo o aparato que dava suporte à clausura real, portanto, sofre influxos dessas transformações. A releitura de fundamento, sentido e finalidade dos institutos fundamentais de Direito Civil, então, deságua na ordem regente das titularidades. E traz consigo uma recompreensão da técnica legislativa empregada no governo jurídico do objeto, de modo a torna-la consentânea às constituições formal, substancial e prospectiva do Direito Privado ${ }^{8}$.

concreta da Constituição, dando-lhe significado" (FIORAVANTI, 2001, p. 814). Tradução livre. No original: "Per 'modello costituzionale' intendiamo quel l'insieme di convinzioni medie, degli interpreti, della classe politica, degli stessi cittadini, che determinano la vita concreta della Costituzione, attribuendole un significato prevalente".

6 "Nesse sentido, parte-se do pressuposto de que o direito é, sim, um sistema e, portanto, demanda para seu funcionamento coerência e harmonia entre seus diversos elementos, mas o sistema do direito não é fechado, ou axiomático, pautado pela lógica formal e pela neutralidade dos enunciados, como se pretendera sob uma perspectiva hermética e autorreferenciada, de matriz positivista. Trata-se de um sistema aberto, em constante estado de complementação e evolução em razão da provisoriedade do conhecimento científico e, principalmente, dos próprios valores fundamentais da ordem jurídica (...). Por conta disso, o sistema permite - rectius, exige - a sua constante renovação por meio da introdução de elementos extraídos da realidade social" (KONDER, 2015, p. 199).

7 É dizer: "Sucumbe a completude como dogma que a teoria tradicional do Direito Civil, em constante visão de excludência social (por vezes direta, em outras indireta), pela compreensão do sistema como aberto, visto não se exaurir em regras, incompleto porém sempre completável sob pena de anomia - por inexistir lacuna de valores - que conduz a necessidade de resposta e proximidade social do Direito para com o destinatário da ordem jurídica” (ARONNE, 2006, p. 46).

8 Constituição formal, nesta ordem de ideias, corresponde às normativas positivadas integradoras do bloco de constitucionalidade que confere unidade e hierarquia ao ordenamento; constituição substancial corresponde a principiologia axiológica de índole constitucional, que permeia dispositivos formalmente insertos no texto da Constituição, mas também outros espraiados por outros diplomas normativos; prospectiva, enfim, é a constituição que se faz pela via da atividade hermenêutica, centrada na atribuição de sentido aos significantes que integram o governo jurídico das relaçôes interprivadas, à vista não apenas das normativas constitucionais e infraconstitucionais, mas também da força normativa dos fatos. A propósito: "a dimensão constitucional do Direito Civil brasileiro contemporâneo abarca, ao lado dos horizontes formais e substanciais dessa base, a perspectiva de reconstrução incessante do próprio Direito Civil para que, no limite, acerte o passo com as demandas de seu tempo, e na possibilidade, contribua na edificação da justiça" (FACHIN, 2012, p. 363). Para uma leitura mais aprofundada da tríplice constituição do Direito Civil, cf., a propósito dessa categorização: FACHIN, L. E. Direito Civil: sentidos, transformações e fim. Rio de Janeiro: Renovar, 2015. 
Sobre este pano de fundo é que se propõe o escrutínio do acórdão pelo qual o STJ julgou o REsp 1.546.165/SP, no sentido de reconhecer o caráter real da multipropriedade imobiliária. Sem embargo da apreciação de aspectos materiais do caso, convirão alguns apontamentos de ordem processual - o que é inevitável quando se trabalha com estudo de decisões judiciais.

\section{DIREITO REAL E SEGURANÇA JURÍDICA PARA ALÉM DO NUMERUS CLAUSUS (?)}

Os direitos reais, no Direito Civil brasileiro, foram "enfeixados sob o princípio da criação exclusiva do legislador, num rol taxativo (numerus clausus), atendendo, assim, as implicações sociais que o sistema leva em conta para excluir tal poder criador da vontade dos interessados" (FACHIN, 1995, p. 161-2). Mas é admitida a criação por via legislativa esparsa, para além do Código Civil, portanto - o principal exemplo, já desgastado, é o do direito real de aquisição atribuído ao compromissário comprador pelo compromisso irretratável de compra e venda, ainda sob a regência do Código Civil de 1916. Assim:

os direitos reais, ao contrário dos pessoais, são númerus clausus, isto é, decorrem diretamente da lei, não sendo possível a criação, pela autonomia privada, de novos vínculos reais. Eis o princípio da taxatividade (...) [que] concerne à fonte do direito real; a tipicidade, por sua vez, se refere à modalidade de se exercício, vale dizer, à disciplina jurídica que lhe é aplicável. (OLIVA e RENTERÍA, 2016, p. 3)

Esta escolha - e o regime jurídico que a encerra - reflete opções de cunho político quanto ao estatuto jurídico do objeto, caros a um dado entendimento de Estado, Direito e segurança jurídica ${ }^{10}$. Assim é que a recompreensão do sentido da

9 Optou-se pela ênfase a esse exemplo por ser ele sinal da força jurígena dos fatos: o direito real de aquisição do compromissário comprador somente adentrou a seara da legislação depois de longo período de maturação no seio social, oxigenada por riquíssima casuística. Outras ilustrações, contudo, há: "Mesmo que recorrente a ideia de taxatividade do rol de direitos reais inscritos no art. 1.225 do Código Civil, não se pode esquecer que, embora não previstos a propriedade resolúvel e a propriedade fiduciária são considerados abertamente direitos reais. Ao que parece a existência de um numerus clausus não pode representar a impossibilidade de consagração de novos direitos, haja vista, a dinâmica social e o aperfeiçoamento jurídico às novas realidades, tal como ocorreu, por exemplo, com a criação do direito de superfície e a vedação de constituiçãa de novas enfiteuses" (STAFFEN e BRANDÃO, 2011, p. 449).

10 Muito em síntese: “[A] segurança jurídica não pode seguir sendo concebida como um valor dependente unicamente dos traços formais do direito, à margem de seu conteúdo. Dito de outro modo, para determinar as distintas exigências que implica o princípio de segurança, precisamos estabelecer quais são as expectativas que merecem ser juridicamente protegidas; neste sentido, se propôs redefinir a segurança jurídica em termos de proteção de expectativas 
propriedade - não mais como um direito absoluto tout court, mas como um direito, se bem que fundamental, funcionalizado - operou pela via dos textos constitucionais ${ }^{11}$, ao menos no Brasil. Isso mesmo com a afirmação, malgrado alguns temperos, de uma constituição econômica de viés capitalista ${ }^{12}$. Das rupturas do discurso proprietário caro ao modelo de Estado de Direito, sintomizadas pela imbricação das constituições formal, substancial e prospectiva do Direito Civil na mundividência contemporânea do Estado Constitucional, exsurge "imensa dificuldade para a doutrina, acostumada ao numerus clausus e à tipicidade dos direitos reais, bem como à solidez da dogmática acerca da propriedade", de modo que "voltam-se [as atenções] para o direito de superfície, a multipropriedade e o condomínio de fato" (MATTIETTO, 2005, p. 163). E é precisamente do caráter político e econômico dos condicionantes da disciplina jurídica da apropriação que deriva a temática enfrentada da multipropriedade:

O tratamento jurídico dos direitos reais não se faz de modo hermético, critérios sociais, ideológicos, econômicos e políticos determinam com maior ou menor intensidade os critérios de exercício de tais direitos. É justamente com base em determinantes de ordem econômicas [sic] que se observa o nascedouro da multipropriedade (STAFFEN e BRANDÃO, 2011, p. 443).

A revisitação da clausura real, destarte, afigura-se como imperativo haurido do horizonte que o Estado e a sociedade contemporâneos apresentam quanto à regência dos direitos reais (cf. FACHIN, 1995, p. 163). Nem poderia ser diferente, pois é

razoavelmente fundadas dos cidadãos (é dizer: expectativas que sejam consideradas legítimas à luz dos princípios e valores do próprio direito)". Tradução livre. No original: "la seguridad jurídica no puede seguir siendo concebida como un valor dependiente únicamente de rasgos formales del derecho, al margen de su contenido. Dicho de otro modo, para determinar las distintas exigencias que implica el principio de seguridad necesitamos establecer cuáles son las expectativas que merecen ser jurídicamente protegidas; en este sentido se ha propuesto redefinir la seguridad jurídica en términos de protección de expectativas razonablemente fundadas de los ciudadanos (es decir, expectativas que han de ser consideradas legítimas a la luz de los principios y valores del propio derecho)" (VIDAL, I. L. Seguridad jurídica y previsibilidad. DOXA Cuadernos de Filosofía del Derecho, n. 36, p. 85-105, 2013, p. 103).

11 A propósito: "O Direito das Coisas, como se tem percebido, é possivelmente a área mais sensível do direito privado, suscetível de refletir uma dimensão política do ordenamento, cuja nota de historicidade se faz presente nos textos constitucionais contemporâneos" (MATTIETTO, 2005, p. 155).

12 Trata-se do conjunto de preceitos e instituições jurídicas que, garantindo os elementos definidores de um determinado sistema econômico, instituem uma determinada forma de organização e de funcionamento da economia e constitui, por isso mesmo, uma determinada ordem econômica. Não são mais as leis naturais do mercado. Quem diz a economia que se deve ter em determinado país é a constituição (cf. MOREIRA, 2006, p. 103-113). 
sinal de significativa ruptura no discurso legislativo (cf., a propósito, CORTIANO JUNIOR, 2002), haurida da constatação de que "o civilismo pretensamente neutro (...) não conseguiu disfarçar que não responde aos fatos e às situações que brotam da realidade contemporânea" (FACHIN, 2012, p. 12). E ela está para além da revisitação, decerto mais palatável à comunidade jurídica especializada, apenas do papel da autonomia privada (como expressão sintética de uma liberdade ao mesmo tempo negativa e positiva ${ }^{13}$ na conformação do conteúdo dos direitos reais ${ }^{14}$. Vale dizer: no bojo das viragens inerentes à travessia do Estado de Direito ao Estado Constitucional, sobretudo no que pertine às relações entre legislação e jurisdição e à revisitação dos institutos fundamentais de Direito Civil, a existência de posições jurídicas credoras de tutela, mas desamparadas pela apatia do legislador clama, em prol da afirmação da segurança jurídica, de atuação resoluta da Jurisdição - em particular, no âmbito das Cortes Supremas, sob olhares atentos da literatura especializada.

A rigidez do numerus clausus, em grave descompasso com a realidade social, suscita esgotamento deste modelo normalizador da apropriação de bens ${ }^{15}$, à moda do que ocorreu com o modelo alemão codificado de reparação civil, cuja predominante tipicidade conduziu a sua abertura pela atuação criativa e prospectiva das Cortes, sem prejuízo de uma fuga para a responsabilidade contratual. Comporta,

$13 \mathrm{O}$ aspecto negativo reside na delimitação de um espaço de não coerção. Quanto à dimensão positiva:" $[\mathrm{A}]$ autorregulamentação de interesses privados que a autonomia privada acaba por assegurar consiste, a rigor, em uma expressão de liberdade formal. Não deixa de ser liberdade positiva, mas é pensada em termos abstratos: é formalmente assegurada a todos a possibilidade de contratar definido o conteúdo da avença que obrigará o contratante" (PIANOVSKI RUZYK, 2011, p. 271).

14 Esta tese foi brilhantemente sustentada por Oliva e Rentería (2016, p. 3 e 7), que dizem: "os direitos reais, ao contrário dos pessoais, são números clausus, isto é, decorrem diretamente da lei, não sendo possível a criação, pela autonomia privada, de novos vínculos reais. Eis o princípio da taxatividade (...) [que] concerne à fonte do direito real; a tipicidade, por sua vez, se refere à modalidade de se exercício, vale dizer, à disciplina jurídica que lhe é aplicável. (...) [Esses princípios] não significam supressão da liberdade contratual em matéria de direitos reais. Se é verdade que a criação de uma nova figura real depende do legislador, certo é também que a autonomia negocial se manifesta de diversas outras maneiras no âmbito dos direitos reais admitidos na lei. (...) Com efeito, os tipos reais são abertos, coexistindo, no interior de cada tipo, regras essenciais e outras que podem ser livremente modificadas pelas partes".

15 A propósito: "Em áreas tradicionalmente isoladas, como Direito Reais, todo o esforço de reconstrução do jurídico tarda. E assim sendo, as soluções novas, ditadas por exigências actuais do Direito, carentes de justificações, amparam-se em cripto-fundametações, meio privilegiado para conseguir saídas inconvenientes ou indemonstradas. Vitimada pelo imobilismo legislativo e pelo irrealismo metodológico, a disciplina Direitos Reais pareceria condenada a uma paralisia definitiva" (MENEZES CORDEIRO, 1985, p. 90-91). 
pena de frustrar a legitimidade do Direito - visceralmente ligada à segurança que oferece ao tráfego jurídico ${ }^{16}$ e à efetividade de suas normativas - e prejudicar a promoção de liberdade(s) na vida-em-relação ${ }^{17}$. Destarte, sob a ótica Civil-Constitucional, em sua contemporânea multiplicidade, cabe, em nome da efetividade do Direito e (por consectário) da segurança jurídica, reconhecer que: "O numerus clausus, em verdade, mais que ensejador de insegurança jurídica, pode se converter em fenda a separar a ordem jurídica dos modelos socialmente reconhecíveis de apropriação dos bens” (MATTIETTO, 2005, p. 164). Via de consequência:

"defender piamente a taxatividade e imutabilidade dos Direitos Reais, inscritos no art. 1.225 do Código Civil, na própria legislação encontra óbices. Neste sentido, como elemento de abertura discursiva vale adotar uma dogmática que, além de um esteio conceitual estável (segundo a ideia de segurança jurídica), efetive uma suficiente mobilidade de pensamento a fim de poder mantê-lo nas distintas e mutáveis situaçôes. Compreender o instituto da multipropriedade, enquanto fenômeno jurídico-social implica na arguição da congruência da disciplina jurídica às exigências fáticas - a (possível) conciliação entre o posto e o pressuposto. Utilizou-se, para o desenvolvimento da pesquisa, o método indutivo, operacionalizado pelas técnicas de conceitos operacionais e da pesquisa bibliográfica” (STAFFEN e BRANDĀO, 2011, p. 444).

Foi exatamente a essa solução que chegou o voto prevalente no acórdão que pôs termo ao REsp 1.546.165/SP. O Ministro João Otávio de Noronha, ao apreciar

16 Cavalcanti Filho já dizia, nos idos da década de 1960: "A ordem jurídica positiva (...) gira em tôrno de uma necessidade de ordem, de segurança". Mas "As ideias de certeza e de segurança, por isso mesmo precisam amoldar-se à realidade que se tem em vista, e que outra não é senão a realidade humana. Por isso mesmo, não se pode jamais cogitar de uma certeza total, de uma certeza absoluta. Sòmente seria possível uma certeza em grau elevadíssimo, uma segurança extremada, se se concebesse, à maneira dos juristas do século passado, a certeza em sentido puramente formal. (...) Tal modalidade de certeza, porém, que se alcançaria através da expressão formal, nenhuma relevância teria, pois a certeza que se deve aspirar é aquela que serve de instrumento de estabilidade e de segurança para a vida social. Ora, a certeza meramente formal é algo abstrato, vazio, inconsistente. A certeza de que cogitamos é uma certeza concreta, na qual o aspecto formal se ajuste aos valores predominantes em uma dada coletividade e corresponda, assim, às aspirações que dela despontam (1964, p. 51 e 159-160).

17 Já se teve a oportunidade de sustentar que: "parece seguro afirmar que o Direito Civil, como continente da 'disciplina positiva da atividade de convivência da pessoa humana com outras pessoas', corresponde à normatividade que 'tutela os interesses dos homens em relação com outros homens nos vários planos da vida onde essa cooperação entre pessoas se processa, formulando as normas a que ela deva se sujeitar'. Adquire, destarte, o sentido de promotor da autonomia da pessoa no desenvolvimento de sua personalidade na vida-em-relação com outras pessoas, a qual está sujeita à incidência direta da normativa constitucional, sobretudo em sua dimensão axiológica, no prisma da coexistencialidade, à luz das normativas hauridas de fatos sociais e das Constituições Democráticas” (ARNT RAMOS, 2017, p. 28). 
uma circunstância fático jurídica peculiar - a entabulação de direito de uso e fruição de determinada coisa por pluralidade de pessoas segundo critérios temporais -, nela vislumbrou elementos caracterizadores dos direitos reais. Endossou, então, a orientação de Tepedino (1993, p. 58-59), no sentido de que:

Os direitos reais têm por objeto imediato uma coisa, com a qual se estabelece seu titular um liame estreito, direto, sem intermediário. A situação jurídica assim constituída tem caráter absoluto, criando um dever jurídico negativo, prevalente contra todos erga omnes -, que deverão respeitar o exercício do direito, abstendo-se de qualquer inferência. $\mathrm{O}$ vínculo jurídico, portanto, adere à coisa sobre a qual incide e tem eficácia generalizada. (...) De tais considerações decorre o caráter real da multipropriedade imobiliária.

Fez-se, então, consignar, no voto em referência, que "extremamente acobertada por princípios que encerram os direitos reais, a multipropriedade imobiliária (...) detém forte liame com o instituto da propriedade, se não for sua própria expressão". A premissa de que se partiu, por conseguinte, é a de que existe uma circunstância que, segundo critérios de valoração jurídico-materiais se credencia ao atributo de direito real, exceto pela afetação de seus contornos a um tipo previsto em lei.

Adiante, anotou-se que o "inconcebível descuido do regulador de sua disciplina jurídica pela via institucional própria” gera insegurança ao tráfego jurídico. Ocorreu, na leitura do Ministro, "a superação da legislação em vigor pelos fatos sociais", pelo que o julgador não pode ser inIbido de "adequando sua interpretação a recentes e mutantes relações jurídicas, prestar a requerida tutela jurisdicional a que a parte interessada faz jus". E mais: o Código Civil em vigor "seguindo os ditames do estatuto civil anterior, não traz nenhuma vedação nem faz referência à inviabilidade de consagrar novos direitos reais”. Eis, então, a segunda premissa: houve distanciamento entre a legislação e os fatos e não há vedação expressa à consagração de novos direitos reais.

Nesta ordem de ideias, considerada a atribuição constitucional do Superior Tribunal de Justiça, de dizer o sentido do direito federal infraconstitucional legislado (art. 105, IIII, CF), observadas exigências qualitativas de fundamentação, em prol da segurança jurídica e da isonomia, procedeu-se ao seguinte silogismo, ambientado em cenário concernente à multipropriedade imobiliária e timbrado pela delongada inércia do legislador:

Todas as características de direito real estão presentes, exceto pela tipicidade

Inexiste vedação expressa à consagração de direito real atípico

A multipropriedade imobiliária é um direito real

Esta posição, à qual aderiram três dos outros quatro Ministros integrantes do quorum de julgamento, é consentânea com o diagnóstico a que se procedeu nas 
linhas precedentes ${ }^{18}$. Vale dizer: adéqua-se às exigências impostas pela multifacetada realidade contextual particular à travessia entre os modelos de Estado de Direito e Estado Constitucional, sobretudo por oferecer solução sistemática a um problema especificamente delimitado ${ }^{19}$ e, com isso, promover segurança jurídica de sentido substancial, sem prejuízo da separação de poderes, relida na pauta da recalibragem das relações entre Legislação e Jurisdição, em termos de conferência de autoridade, de necessidade ou dispensabilidade de fundamentação das decisões jurídicas. Assim: "na inexistência de lei, o que é tipicamente escasso no Direito Privado, a criação normativa é deixada aos subordinados - juízes e juristas - os quais, contudo, não têm poder para criar leis. Eles devem justificar suas opiniōes. (...) Eles devem buscar autoridade"20 (WATSON, 2004, p. 2).

O voto do relator originário, também amparado por elementos de convicção espraiados pelo estado dos debates a respeito da clausura real na literatura especia$\operatorname{lizada}^{21}$, assentou a impossibilidade de "criação de um direito real propriamente dito,

18 Afirma, isto é, a força jurígena dos fatos. Com isso, acolhe a prescrição de Fachin: "A força dos fatos não deve sofrer um juízo de exclusão, cuja ocorrência ilustra outra dimensão, agora externa, que opera para bem, revelar os valores, por meio dos quais este mesmo sistema inclui ou deixa excluídas da sua esfera jurídica, certas pessoas, bens, coisas ou interesses. Da eliminação e das fronteiras arquitetadas pelo sistema privado tradicional abre-se o Direito Civil contemporâneo ao século XXI" (2012, p. 358).

19 De certa maneira, há um proceder ao mesmo tempo tópico e sistemático, a prestigiar um movimento de oxigenação do ordenamento, em benefício de sua unidade e efetividade. Esta tendência, captada por Menezes Cordeiro, é assim por ele sintetizada: "Recentemente, e mercê, sobretudo, de um labor que, mesmo a nível de discussão teórica dos problemas, tem por imprescindível a consideração permanente da dogmática jurídica, isto é, do Direito enquanto soluções reais e concretas, a Ciência Jurídica tem recuperado potencialidades que a habilitem, de novo, a intervir na realidade jurídico-social. (...) Um Segundo aspecto relevante do pensamento jurídico da actualidade, em torno do qual tem vindo a gerar-se consenso, reside no entendimento do Direito como meio destinado à solução de casos concretos. O Direito existe como ordem positiva, logo efectiva, corporizando-se na regularidade de certas manifestaçôes sociais" (1985, p. 83-84).

20 Tradução livre. No original: "in the absence of legislation, which typically has been scarce for private law, law making is left to subordinates - judges and jurists - who, however, are not given power to make law. They must justify their opinion. (...) They must seek authority".

21 Embora o voto invoque, como elementos de autoridade, argumentos de Gustavo Tepedino e de Frederico Henrique Viegas de Lima, ambos os autores, justamente nos textos indicados, sustentam que a multipropriedade imobiliária é direito real. Algumas passagens em que Tepedino o faz, com as cautelas próprias da defesa de uma tese verdadeiramente inovadora, constam do voto prevalente. Por isso, opta-se por não as transcrever. Viegas de Lima, amparado pelo trabalho de Tepedino e por materiais que se acumularam desde a publicação da tese, foi bastante enfático a respeito: "Na multipropriedade, qualquer que seja a sua forma, existe uma 
devendo-se seguir os tipos reais previstos na legislação especifica, especialmente do Código Civil". Mais que prestigiar a segurança jurídica forma $l^{2}$ almejada pelo desenho de uma tipologia fechada em matéria de direitos reais, anotou diversos aspectos que distinguiram a multipropriedade das formas típicas de direitos reais, sobretudo em função de limitações ao exercício de poderes proprietários. Partiu, ainda, da quádrupla função que Viegas de Lima vislumbra no numerus clausus $^{23}$, para firmar que:

a adoção da forma livre de criação dos direitos reais seria capaz de promover um ambiente de insegurança jurídica aos negócios imobiliários devido à impossibilidade de se prever as formas variadas e criativas de novos direitos reais que surgiriam e os efeitos jurídicos que poderiam irradiar.

A ratio traçada, vê-se bem, mira ao atendimento de uma mesma diretriz constitucional: a segurança jurídica. Mas parte de um sentido de segurança caro ao modelo de Estado de Direito, a segurança como certeza, haurida da pré-determinação de hipóteses normativas, a qual se sustenta epistemologicamente na assunção da coincidência ou unidade entre texto e norma ${ }^{24}$. Muito embora o direito positivo

propriedade temporal. A função do tempo exerce o papel de núcleo central em qualquer das teses. Por isto, a multipropriedade é uma propriedade que tem um início e um fim estabelecidos" (2007, p. 32). Aliás, no que se antecipa, por via diversa da traçada pelo voto prevalente e gizada por este trabalho, firmou: "Admitir ser esta modalidade uma propriedade atípica não viola o princípio de numerus clausus de direitos reais. Nem, tampouco, a tipicidade inerente a estes. Por ser uma modalidade de propriedade comprimida, não se quer dizer que esta não deixe de ser propriedade. (...) Da mesma forma, resta atendido o princípio da tipicidade dos direitos reais quando não se estabelece ser esta modalidade um direito real típico. Ao contrário, a atipicidade é perfeitamente visível nesta forma de propriedade. Isto porque a mesma recolhe atributos de outros direitos reais como condição de existência" (2007, p. 105).

22 Esta noção, cingida na mencionada pré-determinação de hipóteses normativas, encontra expressão bastante elucidativa no comentário de Cortiano Junior (2002, p. 66): "cada problema jurídico deve encontrar uma resposta certo, que deve decorrer de premissas certas, que, no caso, são as proposiçōes que refletem as regras do direito".

23 "A ratio de numerus clausus (...) se integra em um sistema coerente, participando da organização dos direitos reais para possibilitar as seguintes funções: a) a contribuição da publicidade dos direitos reais (...); b) a clareza da existência dos mesmos, para um terceiro (...); c) de proteção da liberdade da propriedade (...); e d) é uma regra de ordem ética e moral, que retira (bane) dos direitos das coisas certos direitos que ainda não possuem uma definição clara, uma vez que são diversos os tipos de relaçôes que podem existir entre uma pessoa e uma coisa" (VIEGAS DE LIMA, 2007, p. 98-99).

24 A advertência de Zaneti Junior (2014, p. 179-180) é emblemática neste ponto: "A teoria da interpretação é central para a correta compreensão da dogmática jurídica contemporânea. $\mathrm{O}$ direito lida com textos. Os textos precisam ser interpretados. Não se podem mais confundir, como se fazia uma vez, texto e norma, o dispositivo e seu sentido normativo. A clareza do 
brasileiro contemple diversos enunciados normativos que referendam esta acepção de segurança - a exemplo da hipótese de cabimento de recurso especial por negativa de vigência a dispositivo de lei (art. 105, III, a, in fine, CF) e de ação rescisória por manifesta ofensa a norma jurídica (art. 966, V, NCPC) - e, portanto, não seja de rigor errada a sua invocação, ela está em descompasso com o estado da Teoria do Direito ${ }^{25}$ e com o contexto dinâmico, de travessia, em que o Direito Civil brasileiro contemporâneo se insere.

Nesta ordem de ideias, o prevalecer da divergência sinaliza a sobrepujança da segurança jurídica substancial - e, consequentemente, das viragens caracterizadoras da instauração do Estado Constitucional - em detrimento da segurança jurídica formal - também dos aspectos distintivos do Estado de Direito. Simboliza um passo não tão tímido em direção à ruptura das amarras modernas que reduzem a Jurisdição à dicção da vontade da lei. Consubstancia, enfim, o brado de Garcin, na célebre Huis Clos, de Sartre ${ }^{26}$ : Pas besoin de gril!

texto pode contribuir para a sua interpretação, mas não a elimina. As normas não se confundem com os textos e o que se aplica no direito são as normas, não os textos". Daí se dizer, e.g., que: "os textos legais (ou enunciados normativos) 'constituem uma mera possibilidade de Direito', pois sua transformação em normas jurídicas 'depende da construção de conteúdos de sentido pelo próprio intérprete' (...). Normas não são, portanto, a matéria bruta do raciocínio jurídico, pois sua formulação depende da inteligência de um (ou mais de um) determinado enunciado estabelecido pelo legislador, por meio de um processo mental de interpretação ou adscrição de sentido" (BUSTAMANTE, 2012, p. 233), pelo que não há correspondência necessária entre texto e norma.

25 “Torna-se claro ainda que toda a estrutura jurídica existe e funciona na medida em que visa a certas soluções: o dado jurídico é, por definição, teleológico, numa fenomenologia que se prolonga na necessidade completamente de, das decisões, ponderar as consequências" (MENEZES CORDEIRO, 1985, p. 89).

26 A referência diz respeito à célebre conclusão a que a personagem chega, talvez na mais conhecida passagem da peça, em tradução livre: "Chega de grelhas! O inferno são os outros". No original: "Pas besoin de gril: l'enfer c'est les Autres" (SARTRE, 1947, p. 93). O sentido bem se adapta às relações entre Legislação e Jurisdição. $\mathrm{Na}$ obra do autor, os outros são o inferno porque a execução de seus projetos de vida conflita com o projeto de vida do eu. Implicam, pois, prejuízo a sua autonomia, a sua liberdade. Assim, malgrado haja uma liberdade imanente do sujeito, a convivência com os outros expõe suas fraquezas. O mesmo se dá com a segurança almejada pela Legislação e pela Jurisdição: a convivência de ambas expõe, reciprocamente, as fraquezas de cada uma. A moderna prevalência da Legislação, constrangida pelas fraquezas que a casuística lhe atribui infalivelmente, tornou-se um verdadeiro inferno à segurança jurídica. José Rodrigo Rodrigues diz que ela consistiria em uma Quimera em função disso (cf. 2012, p. 132-133). A releitura das relações entre Legislação e Jurisdição, ao abalar o centralismo da Lei, vem para domar este monstro, para conter os desconfortos gerados pela exposição da insuficiência da ideia de segurança formal e, de certa maneira, abrandar o fogo do 


\section{CONCLUSÃo}

O acórdão pelo qual a Terceira Turma do Superior Tribunal de Justiça julgou o Recurso Especial n. 1.546.165/SP sinaliza o contexto instável e dinâmico da travessia entre os modelos de Estado de Direito e de Estado Constitucional. As contrastantes razões de decidir invocadas pelos votos colidentes se imbricam, cada uma a seu modo, com os referidos tipos de organização jurídico-política caros à tradição europeia continental na atualidade. A prevalência do voto divergente, neste prisma, indica preferência por ou aproximação ao modelo de Estado Constitucional, no bojo de cujas viragens fundamentais os institutos de Direito Civil são relidos em seus fundamentos, sentido e finalidade, segundo a agenda evocatória pautada pela Constituição.

O problema da clausura real - e o alcance da tipicidade dos direitos reais - foi posto em revista pelo julgado, que, visando a remediar a insegurança gerada pelo engessamento do governo jurídico do objeto e seu descompasso com a realidade cotidiana, reconheceu status de direito real ao conjunto de posições jurídicas enfeixadas pela chamada multipropriedade imobiliária, mesmo à míngua de existência de previsão legal específica. Trata-se de avanço salutar, que permite um melhor equacionamento das Titularidades na juridicidade Civil-Constitucional.

Conquanto a decisão comentada, abstraídas questões alheias à problemática material respeitante ao mérito, corrobore o estreitamento das expectativas circundantes ao governo jurídico das relações interprivadas e as próprias normativas nele albergadas, há, ainda, muito a se fazer. A civilística, no exercício de sua vocação crítica, tem que atuar proativamente, não apenas como instância de controle de e constrangimento à atuação de magistrados e legisladores, mas também como locus de criação de modelos explicativos que provejam confiabilidade à dinâmica inerente ao tripé fundante do Direito Civil. Precisa, vale dizer, acolher a recomendação de Schoppenhauer e ser, simultaneamente e em igual medida, espectadora e atora (Zuschauer und Schauspieler zugleich) ${ }^{27}$ no cenário jurídico, de modo a salvaguardar o seguro exercício das liberdades que compõem o núcleo duro da constituição substancial do Direito Civil.

inferno. Neste giro: "Hoje, ainda com maior ênfase, a ética da confiança no direito positivado a equilibrar-se com a estabilidade de entendimentos jurisdicionais, os quais, por si só, se imutáveis indefinidamente ou mutáveis imotivada ou constantemente também geram insegurança. Tal temperamento passa pelo rigor da fundamentação racional das decisões e alcança o sentido da segurança não apenas como garantia de legítimas expectativas, mas também como incidência material da legalidade constitucional" (FACHIN, 2014, p. 17). 


\section{REFERÊNCIAS}

ARNT RAMOS, A. L. Dogmática e efetividade: o papel da civilística no desbravamento de espaços de liberdades. RBDC, Belo Horizonte, v. 11, p. 17-35, jan.-mar./2017.

ARONNE, R. Sistema Jurídico e Unidade Axiológica: Os Contornos Metodológicos do Direito Civil-Constitucional. In: - Direito Civil-Constitucional e Teoria do Caos: Estudos Preliminares. Porto Alegre: Livraria do Advogado, 2006.

BUSTAMANTE, T. R. Teoria do precedente judicial: a justificação e a aplicação de regras jurisprudenciais. São Paulo: Noeses, 2012.

CAVALCANTI FILHO, T. O problema da segurança no Direito. São Paulo: RT, 1964.

CORTIANO JUNIOR, E. O discurso jurídico da propriedade e suas rupturas: uma análise do ensino do direito de propriedade. Rio de Janeiro: Renovar, 2002.

EHRHARDT JUNIOR, M. A nova ordem das relações privadas dentro de uma perspectiva civil-constitucional e a inadequação do modelo tradicional no estudo do Direito de Danos. Revista do Programa de Pós-Graduação em Direito da Universidade da Bahia, v. 22. n. 24, p. 147-164, 2012.

FACHIN, L. E. Direito civil: sentidos, transformações e fim. Rio de Janeiro: Renovar, 2015.

FACHIN, L. E. Segurança jurídica entre ouriços e raposas. In: PIANOVSKI RUZYK, C. E., SOUZA, E. N., BEZERRA DE MENEZES, J. E EHRHARDT JUNIOR, M. (Orgs). Direito civil constitucional: a ressignificação da função dos institutos fundamentais do Direito Civil contemporâneo e suas consequências. Florianópolis: Conceito Editorial, 2014.

FACHIN, L. E. Teoria crítica do Direito Civil: à luz do novo Código Civil brasileiro. 3. ed., revista e atualizada. Rio de Janeiro: Renovar, 2012.

FIORAVANTI, Maurizio. La trasformazione del modello costituzionale. Studi Storici, Roma:Carocci, ano 42, n. 4, p. 814, out./dez. 2001.

KONDER, C. N. Distinções hermenêuticas da constitucionalização do Direito Civil: o intérprete na doutrina de Pietro Perlingieri. Revista da Faculdade de Direito da Universidade Federal do Paraná, v. 60, n. 1, p. 193-213, jan.-abr./2015.

MATOS, A. C. H. A força normativa dos fatos no Direito de Família nas obras dos Professores José Lamartine Corrêa de Oliveira, Francisco José Ferreira Muniz e Carmen Lúcia Silveira Ramos. In: KROETZ, M. C, p. V. A. Direito Civil: Inventário Teórico de um Século. Curitiba: Kairós, 2012.

MATTIETTO, L. Função social e diversificação do direito de propriedade. Revista da Faculdade de Direito de Campos, a. VII, n. 6, p. 155-169, jun./2006.

MENEZES CORDEIRO, A. Evolução juscientífica e Direitos Reais. Revista da Ordem dos Advogados, 1985. Disponível na Internet via: <https://portal.oa.pt/upl/\%7Be0cc0110ab54-439f-81dc-c2f464acc0b6\%7D.pdf>. Última consulta em 28 de abril de 2017. 
•• Direito Civil: Estudos | Coletânea do XV Encontro dos Grupos de Pesquisa - IBDCivil

MOREIRA, E. B. Os princípios constitucionais da atividade econômica. RFDUFPR, v. 45, n. 0 , p. 103-113, 2006.

OLIVA, M. D. e RENTERÍA, P. Autonomia privada e direitos reais: redimensionamento dos princípios da taxatividade e da tipicidade no direito brasileiro. Civilística.com, a. 5, n. 2, 2016.

PIANOVSKI RUZYK, C. E. Institutos fundamentais do Direito Civil e Liberdade(s): repensando a dimensão funcional do Contrato, da Propriedade e da Família. Rio de Janeiro: GZ, 2011.

PIANOVSKI, C. E. A importância de uma Teoria (Geral) do Direito Civil. In: TEIXEIRA, A C. B. e LEITE, G, p. L. (Coords). Manual de Teoria Geral do Direito Civil. 1a Reimpressão. Belo Horizonte: Del Rey, 2013.

RODRIGUEZ, J. R. Por um novo conceito de segurança jurídica: racionalidade judicial e estratégias legislativas. Analisi e Diritto, p. 129-152, 2012.

SARTRE, J, p. Huis clos. Paris: Éditions Gallimard, 1947.

SCHOPPENHAUER, A. Aphorismen zuer Lebensweisheit. Leipzig: Insel-Verlag, 1917.

STAFFEN, M. R. e BRANDÃO, P. T. Multipropriedade: entre a realidade e os direitos reais. Revista Eletrônica Direito e Política, Itajaí, v. 6, n. 2, p. 442-455, set.-dez./2011.

TEPEDINO, G. Multipropriedade imobiliária. São Paulo: Saraiva, 1993.

VIDAL, I. L. Seguridad jurídica y previsibilidad. DOXA Cuadernos de Filosofía del Derecho, n. 36, p. 85-105, 2013.

VIEGAS DE LIMA, F. H. A multipropriedade imobiliária. RTDC, v. 32, p. 73-109, out.dez. $/ 2007$.

WATSON, Alan. Legal culture $v$. legal tradition. In: van HOECKE, Mark (Org.). Epistemology and methodology of comparative law. Oxford: Hart, 2004.

ZANETI JUNIOR, H. Cortes Supremas e Intepretação do direito. In: GALLOTTI, I. et al. (Coords.). O Papel da Justiprudência no STJ. São Paulo: RT, 2014. 